\title{
STRATHCLYDE
}

DisCuSSION PAPERS IN ECONOMICS

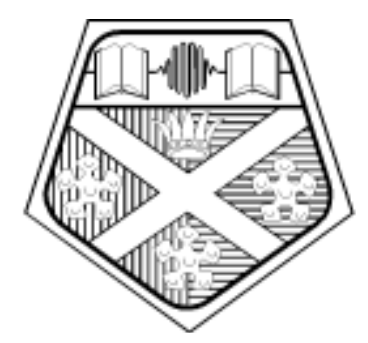

INTRA-GROUP COMPETITION AND INTER-GROUP CONFLICT: AN APPLICATION TO NORTHERN IRELAND.

BY

\section{COLIN JENNINGS}

No. 08-09

DEPARTMENT OF ECONOMICS

UNIVERSITY OF STRATHCLYDE

GLASGOW 


\title{
Intra-Group Competition and Inter-Group Conflict: An
}

\section{Application to Northern Ireland}

\author{
Colin Jennings* \\ The Department of Economics, University of Strathclyde, Glasgow, G4 0GE, UK. \\ colin.jennings@strath.ac.uk
}

\begin{abstract}
This paper reviews four economic theories of leadership selection in conflictual settings. The first of these by Cukierman and Tomassi (1998) labeled the 'information rationale', argues that hawks may actually be necessary to initiate peace agreements. The second labeled the 'bargaining rationale' borrowing from Hamlin and Jennings (2007) agrees with the conventional wisdom that doves are more likely to secure peace, but post-conflict there are good reasons for hawks to be rationally selected. The third found in Jennings and Roelfsema (2008) is labeled the social psychological rationale. This captures the idea of a competition over which group can form the strongest identity, so can apply to group choices which do not impinge upon bargaining power. As in the bargaining rationale, dove selection can be predicted during conflict, but hawk selection post-conflict. Finally, the expressive rationale is discussed which predicts that regardless of the underlying structure of the game (informational, bargaining, psychological) the large group nature of decision-making by making individual decision makers non-decisive in determining the outcome of elections may cause them to make choices based primarily on emotions which may be invariant with the mode of group interaction, be it conflictual or peaceful. Finally, the paper analyses the extent to which the theories can throw light on Northern Ireland electoral history over the last 25 years.
\end{abstract}

JEL Codes: D72, D74

Keywords: Conflict, leadership, strategic delegation, consociation, Northern Ireland

\footnotetext{
* I would like to thank Geoffrey Brennan, Alan Hamlin, Hein Roelfsema and participants at the Public Choice Meetings in Amsterdam (2007) and San Antonio (2008) and the Economics Department workshop at Edinburgh University for their helpful comments.
} 


\section{Introduction}

The extent to which we observe the existence of group conflict is heavily determined by the choice of group representatives. Whether conflict is based on class, nationalism, religion (or ethnicity in general) there usually exists a choice of leadership which is either moderate/dove or extreme/hawk. It is generally thought that the selection of hawks is a major cause of conflict and it is often lamented (especially by those viewing from the outside) that if only the groups involved could disregard their emotions and think rationally, they would choose moderate leaders who would more likely find a resolution and establish cooperative institutions. Similarly, if peace agreements have somehow been forged it is often the hope of the outside world that group identities will break down and divisive societies will integrate. It is frustrating when cooperative institutions sometimes seem to lead to a heavier selection of hawks rather than doves thus undermining further integration.

The approach of this paper is that of a rational choice/economic attempt to analyse the effect of group heterogeneity (in terms of group members' attitudes towards the other group) and the nature of individual group member's motivation when selecting the leader who will represent the group. These are topics that the economic approach to conflict has tended to neglect. Garfinkel and Skaperdas (2007) and (more briefly) Skaperdas (2006) provide a comprehensive overview of this literature. The baseline model is a game in three stages. In stage one, homogenous groups (so they can be treated as a single agent) decide upon their investment in guns versus butter. Gun production reduces butter and thus utility. The investment in guns determines the probability that the group will succeed in a contest with other groups, if such a contest were to arise. In stage two, negotiation takes place and if this fails conflict will occur in stage three. The baseline model has provided considerable light on the costs of conflict (even when it does not occur), rational reasons for conflict to exist and the application of the model to areas such as trade and security. The model has also been relaxed to allow for strategic interaction amongst group members. The key lesson of this analysis of inter and intra group competition is that we can expect to see freeriding in group activity in the contest between groups where the gains are public, but 
greater effort to acquire the spoils of a successful conflict if the gains are allowed to be private.

The analysis of this paper diverges from the core literature by taking a different perspective on intra-group strategic interaction and thus the underlying motivation of group members when making their choice of group leader. In the rationales to be discussed we drop the assumption that group members are homogenous in their preferences and that the underlying motive for group activity is necessarily to acquire the resources belonging to the other side. In most conflicts there tends to be a distribution of preferences with regard to the depth of feeling of group identity or the level of antipathy towards opposing groups. Furthermore, conflicts do not always appear to be economically motivated. Conflicts may arise when there is no (or at least no obvious) attempt to acquire resources, but rather to impose ideology or compete over identity. The survey of possible rational rationales developed here will, we hope, address to some extent these two lacunae in the existing literature.

By considering intra-group competition as a determinant of the degree to which we observe inter-group conflict, the paper is close in spirit to the work of Bueno de Mesquita, Morrow, Siverson and Smith (2002), Bueno de Mesquita, Siverson and Morrow (2003) and for an overview Bueno de Mesquita (2006). This approach, which we might label the 'domestic perspective' attempts to move away from structural theories of international relations which treat nations as organic units and ignores the effect of domestic politics on foreign policy. They argue that domestic politics, in fact, has a major impact upon the interaction between countries. This is certainly the case in the rationales to be studied in this paper and we extend this reasoning beyond nations to interactions between groups in general and where intra-group competition has major effects.

The intra-group competition we focus on is that between moderates and extremists. We review four economic theories that attempt to make sense of leadership selection in conflictual settings. The first of these by Cukierman and Tomassi (1998) we label the information rationale, argues that hawks may actually be necessary to initiate peace agreements. The second labeled the bargaining rationale borrowing from Hamlin and Jennings (2007) agrees with the conventional wisdom that doves are more likely to secure peace, but post-conflict there are good reasons for hawks to be rationally selected. The third found in Jennings and Roelfsema (2008) we label the social psychological rationale. This captures the idea of a competition over which 
group can form the strongest identity, so can apply to group choices which do not impinge upon bargaining power. As in the bargaining rationale, dove selection can be predicted during conflict, but hawk selection post-conflict. Finally, we discuss the expressive rationale which predicts that regardless of the underlying structure of the game (informational, bargaining, psychological) the large group nature of decisionmaking by making individual decision makers non-decisive in determining the outcome of elections may cause them to make choices based primarily on emotions which may be invariant with the mode of group interaction, be it conflictual or peaceful. In each of the rationales we look at the implications for inter-group conflict and make some simple welfare judgements. The political situation in Northern Ireland provides an opportunity to apply the analysis. We discuss how the rationales link to the relatively recent history of Northern Ireland and a sample of the literature that has been analysing it.

It should be noted at the outset that the rationales to be discussed here have all been published. To that end, the novelty of this paper is not by presenting fresh theories. Rather, the novelty is in the collection of the rationales and their application to the case of Northern Ireland (though it is hoped that the application is more general than that). However, revisiting the rationales does allow the opportunity to present them in more simplified forms and in some cases to explore issues not addressed in the original versions.

\section{The Information Rationale}

Cukierman and Tomassi (1998) set out to explain why some major policy initiatives are taken by seemingly the least likely policy makers. They discuss major free market reforms taken by left-wing parties, but of direct relevance to this paper they also discuss the pursuit of peace deals by politicians associated with being hawks. The title of their paper gives one example of Nixon opening the way to cooperate with China. Another example they provide is the peace deal forged between Israel and Egypt by Begin and Sadat, both considered to be hawks.

The logic of their argument is as follows. Within any nation (and we extend the notion to groups in general) there may exist hawk and dove parties. Either of these will be dominant at a particular point in time and will either be the incumbent power, or could be treated as such. All parties are assumed to have two goals. First, they want to win 
elections. Second, they are outcome oriented and wish to implement policies that provide their ideal outcomes. However, polices and outcomes are not perfectly mapped. Occasionally, for example, a hawk may find that pursuing a dovish policy is more conducive to achieving their hawkish goal.

Assume that there is a hawk incumbent and that they have received a signal that a dovish policy is optimal to achieve a hawkish end. The incumbent hawk must weigh two counteracting effects. By pursuing a dovish policy, voters are sent a signal that dovish policies might work better. The median voter will form the expectation that if a hawk is pursuing a dovish policy then an implication is that an even more dovish policy may be required to achieve the goals of the median voter. This makes the hawk less electable and they call this the 'expectations effect'. On the other hand, by moving towards the dovish policy they move towards the median voters making them more electable. They label this the 'Hotelling effect'. From the perspective of voters there are two random effects that they cannot observe directly. These are the mapping of policy into outcome and party ideology. Cukierman and Tomassi argue that political parties tend to be coalitions of various interest groups, any of which may be more or less influential within the party at any point in time in a way that is not clear to the voter.

The key result is the following. When the variance of party ideology is greater than the variance of the mapping of policy into outcomes, the hawk incumbent is more electable because the Hotelling effect is greater than the expectations effect. In other words, the moderation shown by the hawk party is attractive to voters given the spread of opinion they believe exists within that party. They form the view that the moderate wing of the party is winning. This is combined with the view that it is less likely that the stance is driven by the hawk incumbent receiving dovish signals. The conclusion is that under these circumstances, extreme dovish policies are more likely to be implemented by hawks. Were the incumbent a dove and they implement extreme dovish policies, this will be interpreted as a swing to the extreme dove end of the party and will make them less electable. In order to win the election, the dovish party would be well advised to hide the signal. A hawk incumbent would have no such concern because they know that the peace agreement they would make would be viewed as credible.

So this analysis overturns the conventional wisdom. It should be noted that if the expectation effect outweighs the Hotelling effect then a dove incumbent would find it 
electorally profitable to implement extreme dovish policy. The pursuit of such policies therefore depends on the identity of the incumbent party, the mix of preferences within it and the nature of the signals received by the public. As we shall see, in the Northern Ireland case, it also depends on whether the incumbent is willing to take major risks with regard to retaining power. In Cukierman and Tomassi's analysis the nature of any peace agreement is not explored, but presumably we may expect the identity of negotiators to influence what sort of deal (if any emerges). This leads naturally to a discussion of the bargaining rationale.

\section{The Bargaining Rationale}

Cukierman and Tomassi assume the existence of a dove and a hawk and don't model the possible entry of centrists into the electoral competition. If they did, one might be tempted, according to the median voter theorem, to think that a centrist party (neither hawk nor dove) will win. In the following two sections we shall see that this is not true if we model voters as choosing strategically. The median voter will want the political outcome to be located at her ideal point, however, given the nature of the political game achieving this goal may be better served by selecting a leader with a preference different to her own. Indeed, given a lack of information the previous section has shown us that the median voter may prefer an extreme hawk to make a peace agreement in order to render it credible. A large literature now exists on the role of strategic delegation in political settings. Examples are Chari, Jones and Marimon (1997) who use strategic delegation to explain the practice of split-ticket voting in the US, Persson and Tabellini (1992) who predict that more liberal representatives would be elected to counter the effect of the tax base being reduced through increased tax competition in Europe following the increased integration of 1992, and Besley and Coate (1997) use strategic delegation to endogenize leadership in their citizen candidate model.

We provide a simplified version of the analysis in Hamlin and Jennings (2007) to study the bargaining rationale for leadership selection in conflict. Assume that all members of a population have joined one of two groups that formed out of a population whose ideal points in policy space are distributed uniformly on $[0,1]$. We now use a two-stage game to depict leadership selection. In stage 1 of the game a leader is selected where there is an available potential leader across the full spectrum 
of the group, taking the choice of leader by the other group as given. In stage 2 leaders choose their mode of interaction and the social outcome is determined. As usual, it is appropriate to consider these stages in reverse order to find subgame perfect equilibria of the game.

\subsection{Stage 2 - The Game of Political Interaction}

Whichever leaders emerge in each group, and however they emerge, they will find themselves playing a stage game against the opposing leader which will determine the overall outcome for members of both groups. We endogenise the choice of the form of the interaction between groups - whether violent conflict (con) or peaceful compromise (com). If both leaders choose conflict, we assume, initially, that the political outcome is exactly the same as it would have been if they both agreed to compromise - a weighted sum of the two leaders policy preferences - but that both groups carry a cost of conflict. This reflects the idea that conflict may not be decisive in determining the political outcome, but is always costly. This is a sharply different assumption to the standard one where a contest success function is used and one of the groups will emerge as winner. However, stalemate is both a realistic depiction of many conflicts in reality and we will argue potentially increases the level of conflict costs that may be incurred.

$L_{1}$ and $L_{2}$ are the locations or ideal points of the leaders of group 1 and 2 respectively and, without loss of generality, we take $L_{1}$ to be to the left of $L_{2}$, with $L=\left(L_{1}-L_{2}\right)$. We consider the case where the groups are of equal size and strength (encompassing $[0,1 / 2)$ and $(1 / 2,1])$ and we refer the reader to Hamlin and Jennings (2007) for the case of asymmetric groups. The political outcome is given by $L_{1} / 2+L_{2} / 2$ and the payoff to each leader is indicated in terms of the distance from the political outcome to the leaders' ideal points and conflict costs should they be incurred.

The exogenous cost of conflict is indicated by $v$. To hold $v$ exogenous runs contrary to the general spirit of conflict/rent-seeking models as outlined in the introduction. These models focus on endogenising the cost of conflict in terms of resources used for guns rather than butter production in anticipation of/or use on conflict. Nonetheless, these models also often include a predictable, exogenous cost of conflict given by the destruction of resources. We view $v$ in this way, as an expected cost of conflict, but one that is symmetrically perceived. This allows a simplified approach where we can 
focus on leadership selection and the choice between conflict or peace given an exogenous conflict cost. We would also argue that for many conflicts the idea that the cost of conflict is fully incurred after the conflict has been initiated is realistic. The gun versus butter decision focuses on costs incurred in anticipation of conflict. We draw attention to the idea that if leaders can be found who would agree on peace then it is possible that no conflict costs need be incurred at all. ${ }^{1}$

We analyse the following game

\begin{tabular}{c|c|c|}
\multicolumn{1}{c}{$\operatorname{com}$} & \multicolumn{2}{c}{ com } \\
\cline { 2 - 3 } $\operatorname{con} \frac{L}{2}, \frac{L}{2}$ & $L,-v$ \\
\cline { 2 - 3 } & $-v, L$ & $\frac{L}{2}-v, \frac{L}{2}-v$ \\
\hline
\end{tabular}

Figure 1 The Game of Political Interaction

The key point here is that a prisoner's dilemma may emerge with conflict a dominant strategy for each player. This will be the case if:

$$
\frac{1}{2}\left(L_{2}-L_{1}\right) \geq v
$$

however if

$$
\frac{1}{2}\left(L_{2}-L_{1}\right) \leq v
$$

compromise will be the dominant strategy for each player.

\subsection{Stages 1 - Choosing the Leader}

The potential leader must be the Condorcet winner - that is the winner in a straight contest with any other candidate - and thus the choice of the median member of the

\footnotetext{
${ }^{1}$ There has been a recent paper by Brandauer and Englmaier (2006) that extends the contest success function to include heterogeneous preferences. This is clearly an approach close to the one taken here and it might be argued with the added advantage of retaining the central concern with the guns versus butter decision. They find that, in equilibrium, contests are fought between asymmetric leaders (radical and less radical) and that there is lower overall spending on guns compared to non-strategic decisionmaking. In their paper, the contest certainly occurs. The possibility of choosing leaders to avoid conflict is a crucial difference in the approach made by Hamlin and Jennings. However, the finding on the selection of asymmetric leaders is mirrored for certain parameter values and that strategically selected leaders can contain costs compared to median voters sincerely selecting themselves or choosing leaders expressively.
} 
group. The median member of group 1 would be the member located at $1 / 4$. We assume that this member, like all group members, knows the payoffs in the game of political interaction to be played as stage 2, and the value of $v$. The chosen leader of group 1 will then be the best response to the type of leader selected by group 2 . The optimal choice of $L_{1}$ (ignoring $v$ for now) is given by opt $L_{1}=1 / 2-L_{2}$, such that $L_{1} \geq 0$. Since $L_{2}>1 / 2$, opt $L_{1}=0$ and, a similar argument implies that opt $L_{2}=1 .^{2}$

Note that leaders located at 0 and 1 would always be chosen by the median members of their respective groups if the game of political interaction were replaced by a simple compromise with the rival leader. Thus, extremists are always preferred as leaders in respect of their ability to deliver the most advantageous compromise. However, 0 and 1 are also the most likely leadership locations to bring about conflict rather than compromise. Group members, therefore, face a choice between a leader located at 0 (1) with the certainty of conflict, and a leader who is the most left-wing (right-wing) member of the group who would compromise. All leaders other than these two would clearly be dominated. For the median member of group 1 located at $1 / 4$ to choose a leader who would compromise, it must be the case that

$$
\frac{1}{4}-\frac{1}{2}\left(0+L_{2}\right)-v \leq \frac{1}{4}-\frac{1}{2}\left(L_{1(\mathrm{com})}+L_{2}\right)
$$

where $L_{2}$ is any given leader chosen by group 2 and $L_{1(\text { com })}$ is the location of the most left wing compromiser, (3) reduces to

$$
v \geq \frac{1}{2} L_{1(\text { com })}
$$

In turn, for group 2 to be willing to choose a leader who would compromise, it must be that for their median voter (located at approximately $3 / 4$ )

$$
\frac{1}{2}\left(1+L_{1}\right)-\frac{3}{4}-v \leq \frac{1}{2}\left(L_{2(\text { com })}+L_{1}\right)-\frac{3}{4}
$$

This reduces to

$$
\frac{1}{2}-v \leq \frac{1}{2} L_{2(\text { com })}
$$

For two compromise leaders to emerge, (4) and (6) must both hold. We can now make some conclusions about what sort of leaders will emerge, given differing values of $v$.

\footnotetext{
${ }^{2}$ This follows by noting that ideally for $1 / 4$ and $3 / 4,1 / 4=o p t L_{1} / 2+L_{2} / 2$ and $3 / 4=L_{1} / 2+o p t L_{2} / 2$
} 
- When $v=0$, there is by definition no cost associated with conflict, so that conflict is irrelevant to decision making. $L_{1}$ and $L_{2}$ will be located at 0 and 1 , and there will be conflict.

- As $v$ increases from 0 up to $v=1 / 6,0$ and 1 will continue to be the equilibrium leaders and positive conflict costs will be incurred which follows from solving (2), (4) and (6) simultaneously. To see this note that it will not be possible to find values for $L_{1}$ and $L_{2}$ such that (4) and (6) will hold. For instance, assume $v=0.1$, for (4) to hold it must be that $0.2 \geq L_{1}$. However, any individual located at approximately 0.2 would not choose a compromise strategy against any leader that group 2 may choose. As such group 1 would choose 0 as leader and in response group 2 would choose 1 . Therefore, conflict would ensue. Note that the essential reason for this outcome is that $v$ is too low for the cost of conflict to counterbalance the benefits from extreme leaders in terms of their influence on outcomes.

- For values of $v$ between approximately $1 / 6<v<1 / 4$, multiple equilibria exist. For instance at $v=0.2,0.3$ would be willing to compromise against 0.7 . If we plug the values into (4) and (6), both equations hold. However, note that the best response to the choice of 1 as $L_{2}$, would be for group 1 to choose 0 ; similarly, if 0 is elected by group 1, group 2 will elect 1 . Multiple equilibria exist, one of which is conflictual - the election of extremists at 0 and 1 . This raises the problem of coordination between the two groups when choosing leaders.

- For $v=1 / 4$, conflict disappears in equilibrium and at least one leader is not extreme. At $v=1 / 4$, member 0.25 is indifferent between voting for 0.5 or 0 against 1. At conflict costs higher than 0.25 , the compromise leader would always win in response to any leader selected by the other group. Although there remain multiple equilibria, none will be conflictual.

- $v>1 / 2$, there will be no conflict and the groups will select extremists as their leaders. In this case, no leader will actually choose conflict as a strategy in stage 3. The social outcome will be $1 / 2\left(L_{2}-L_{1}\right)$ and therefore 0 would be the preferred leadership location of the median member of group 1, no matter which leader group 2 elects. The same logic applies to group 2. Thus, $L_{1}$ and $L_{2}$ will be located at 0 and 1. 
Three main conclusions emerge. First, extremist leaders always provide the best political outcome from the perspective of the median members of the groups if conflict costs are ignored. ${ }^{3}$ Thus when conflict costs are low, extremist leaders will emerge. But the relationship between conflict costs and the position of leaders is not monotonic. As conflict costs rise, the probability of extreme leaders falls, but if conflict costs rise beyond a threshold level (0.5) conflict is so costly that even extreme leaders will avoid it, so that extreme leaders will reappear. Second, the costliest conflict that will emerge in equilibrium arises when $v=1 / 4$, and is below the level of conflict cost that would be suffered if groups always followed the simple rule of appointing extremist leaders. Third, equilibria involving compromise can emerge at relatively modest levels of conflict cost, for $v>1 / 6$. This should be compared against the idea that the median voters always select themselves. In this case conflict would exist up to $v=1 / 4$ or the costs that could be incurred if leaders were selected expressively which will be the subject of section 5 .

In Hamlin and Jennings conflict was treated as stalemate and that this would be the certain outcome. Contest success functions model conflict as being completely decisive, but with uncertainty over the identity of the winner. The possibility of decisiveness was not explored in the original paper, but it would be instructive to revise the results of this section in the light of assuming decisive conflict rather than stalemate. The payoffs in Figure 1 will remain the same except that those in (con, con) are probabilistic with regard to the political outcome. There is a 50/50 chance that the political outcome will be at $L_{1}$ or $L_{2}$. Assuming the leaders are risk neutral, equations (1) and (2) hold as before. The change comes in the behaviour of the median voters. Clearly if there is to be conflict they are better choosing themselves than extremists. Equation (3) must now be amended to

$$
\frac{1}{2}\left(\frac{1}{4}-L_{2}\right)-v \leq \frac{1}{4}-\frac{1}{2}\left(L_{1(\mathrm{com})}+L_{2}\right)
$$

which reduces to

$$
v \geq \frac{1}{2} L_{1(\text { com })}-\frac{1}{8}
$$

equation (5) now becomes

\footnotetext{
${ }^{3}$ This is not true when groups are highly asymmetric in size and strength, see Hamlin and Jennings for details.
} 


$$
\frac{1}{2}\left(L_{1}-\frac{3}{4}\right)-v \leq \frac{1}{2}\left(L_{2(\mathrm{com})}+L_{1}\right)-\frac{3}{4}
$$

which reduces to

$$
\frac{3}{8}-\frac{1}{2} L_{2(\text { com })}<v
$$

We now find that solving for (2), (8) and (10) simultaneously means that conflict will only exist with certainty up to $v=1 / 12$. Decisiveness prevents delegation to extremists and this in turn contains conflict costs.

Whether the nature of conflict is represented as decisive or non-decisive we might wish to consider the implications of a peace agreement. This would suggest the (com, com) profile, which in turn (for the case of fairly equally sized or powerful groups) would imply the selection of extremists. Given that $v$ is the only source of welfare loss in this model, a political outcome of cooperation with groups led by extremists is efficient as $v$ does not exist.

\section{The Social Psychological Rationale}

Underlying the previous two sections is the idea that the political interaction between groups is driven by disputes over resources or political power more generally. The information rationale was vague on the details of bargaining for the very reason that voters cannot directly observe the nature of any deal. Hawks pursuing peace will be attractive when it makes the potential deal credible. The bargaining rationale is explicit and straightforward. Given a political outcome that is an average of the positions of the leaders, it makes sense for the median voter to select an extremist in order to achieve a favourable distribution of political power. The problem is that choosing extremists may cause conflict and therein lies the trade-off.

So both models, explicitly or implicitly, suggest that hawk selection trades political power against peace and when peace is secured hawk selection dominates the selection of doves. How realistic a depiction of group conflict is this? In some circumstances one might expect the selection of leadership to have little or no effect upon the distribution of power. This might simply be determined by the relative strength of the groups regardless of the choice of leader. In this case, there would appear to be little benefit in choosing any but the most moderate leader since that would more likely bring peace at no cost in terms of lost power. 
In this section we aim to provide a different reason for selecting doves in one type of institutional environment and selecting hawks in another one. This picks up on the work of social psychologists that has provided a focus on competition over identity as the source of conflict. The pioneering work was Tajfel (1981) and Brown (2000, chapter 8) provides an overview of the literature. The key insight is that disputes can arise between groups even when there is no obvious basis for it in terms of disputes over resources or political power. Groups compete to establish superior identities and this competition can be very costly and spill over into violence.

Such a perspective on group conflict seems to move some distance from the standard perspective of economists and may even be viewed by some as irrational. Economists have though become comfortable with the analysis of status competition or 'keeping up with the Joneses' (KUJ) where individuals compete over conspicuous consumption (see Frank (1985) for a pioneering work). Jennings and Roelfsema (2008) take the idea of KUJ and argue that groups may compete over conspicuous public goods (CPGs).

In a non-cooperative state investment in the contest for identity may prove to be very costly either in terms of resources used today in the production of conspicuous public goods or the anticipation of future conflict costs caused by provocative actions today. A first-best solution (in the presence of such externalities) would seem to be centralised decision-making between the group leaders who agree to provide the optimal amount of CPG within their groups. This idea is a standard one in the literature on federalism and the degree of externality provides the basis for deciding which goods should be produced at a centralised level. Besley and Coate (2003) argue that the political process can produce perverse results. When the cost of local public good production is to be shared between two jurisdictions it makes sense for voters in each jurisdiction to select leaders with strong preferences for local public goods as they will be subsidised by the other group. The political process, in this way, undermines the benefits of internalising positive externalities by causing spending to be excessive. Dur and Roelfsema (2005) provide an alternative institutional arrangement such that costs are non-shareable. In this case politicians with weak preferences for local public goods will be elected as the group attempts to free-ride on public good provision by the other group. In this case, the distortion caused by strategic delegation would be towards under-provision. 
Jennings and Roelfsema therefore treat the provision of CPGs as subject to a political process, such that groups can either cooperate or not and leaders are selected in response to the institutional arrangements. By looking at non-shareable cost, in the centralised case they find that (as the result above suggests) hawks are selected so as to free-ride on the restraint shown by the other group (recall that CPGs produce negative externalities). This potentially undermines the benefits of centralisation. This is especially the case since in the decentralised case we should expect strategic delegation to doves as voters anticipate the destructive nature of the KUJ contest. Therefore, in societies where conflict is driven by competition over identity and voters choose strategically then cooperative institutions may simply lead to greater extremism and thus prevents the elimination of welfare loss (due to continuing overinvestment in CPGs). This provides a nice contrast with the 'bargaining rationale' where the rational selection of extremists in cooperative institutions is of no concern normatively as $v=0$, and $v$ is the only source of inefficiency. This captures the 'common sense' understanding that even when cooperative institutions have been agreed the potential for costs (other than conflict costs) to continue may still be deeply ingrained.

We will now provide a brief model which formalises the above discussion. We use a fairly specific utility function, for a presentation using a more general representation and a more detailed discussion see Jennings and Roelfsema.

\subsection{The Model}

Consider two groups indexed by $i$, each inhabited by a continuum of citizens $j$. The typical citizen has a utility function of:

$$
U^{j}\left(g_{i}, g_{-i}, \lambda^{j}\right)=y-c g_{i}+h\left(g_{i}, g_{-i}, \lambda^{j}\right)
$$

where $g_{i}$ are the CPGs in group $i$ and $g_{-i}$ are CPGs in group $-i, y$ is income that is identical for all individuals, $c$ is the constant marginal production costs of a unit of $g_{i}$ (so that $y-c g_{i}$ is the consumption of private goods), and $\lambda^{j}>0$ is the preference parameter for public goods. For the $h$-function we assume the following derivative properties: $h_{i}>0, h_{-i}<0, h_{\lambda}>0$. In the following, we will consider the case where CPGs are strategic complements such that $h_{12}>0$. This captures the KUJ effect, as 
the marginal utility of public goods in group $i$ increases in the level of public goods in group -i. For simplicity, we propose the following utility function.

$$
V_{i}^{j}=\lambda_{i}^{j} \log \left(g_{i}-\alpha g_{-i}\right)+y-c g_{i}
$$

We assume that the parameter $\alpha$ is identical for all citizens. This parameter measures the extent to which CPGs are strategic complements. A high $\alpha$ means that the individual greatly envies CPG provision in the other group. A positive $\alpha$ also means that higher $\mathrm{CPG}$ provision in the foreign group raises the marginal utility of home production of CPGs. Foreign production of CPGs creates a negative externality in the home group. Producing one unit of $g_{i}$ involves a fixed marginal cost per unit, that for simplicity we have normalized so that $c=1$. As noted above the costs of CPGs should be considered broadly. They may entail high level resource costs today, for example, building monuments or investing in cultural programmes and so on. Alternatively, a provocative speech is effectively free of resource costs today but it may entail high expected costs if it leads to violent confrontation.

Suppose that in a decentralized political system the median voter $j=m$ is elected as policy maker. From the first-order condition of (12) it follows that:

$$
\frac{\lambda_{i}^{m}}{g_{i}-\alpha g_{-i}}-1=0 \quad \Rightarrow \quad g_{i}=\alpha g_{-i}+\lambda_{i}^{m}
$$

In equilibrium, the level of public goods is:

$$
g_{i}=\frac{1}{1-\alpha^{2}} \lambda_{i}^{m}+\frac{\alpha}{1-\alpha^{2}} \lambda_{-i}^{m}
$$

In the symmetric equilibrium $\left(\lambda_{i}^{m}=\lambda_{-i}^{m}\right)$ equation (14) reduces to:

$$
g_{i}=\frac{\lambda_{i}^{m}}{(1-\alpha)}
$$

Clearly, the decentralized equilibrium level of public goods supply is increasing in the preferences $\lambda$ of the median voter and increasing in the level of $\alpha$.

To elaborate on the oversupply of local public goods, consider the socially optimal level of production $V_{s}=V_{i}^{m}+V_{-i}^{m}$. The first-order conditions for $g_{i}$ and $g_{-i}$ that maximize $V_{s}$ are:

\footnotetext{
${ }^{4}$ To be precise, in order to imply that the two median voters leading their groups is socially optimal we are assuming normal or uniform distribution of preferences within the two groups.
} 


$$
\begin{gathered}
\frac{d V_{s}}{d g_{i}}=\frac{\lambda_{i}^{m}}{g_{i}-\alpha g_{-i}}-\alpha \frac{\lambda_{-i}^{m}}{g_{-i}-\alpha g_{i}}-1=0 \\
\frac{d V_{s}}{d g_{-i}}=\frac{\lambda_{-i}^{m}}{g_{i}-\alpha g_{-i}}-\alpha \frac{\lambda_{i}^{m}}{g_{i}-\alpha g_{-i}}-1=0
\end{gathered}
$$

After considerable manipulation we find that in equilibrium:

$$
g_{i}=\frac{1}{1+\alpha} \lambda_{i}^{m}+\frac{\alpha}{1+\alpha} \lambda_{-i}^{m}
$$

In the symmetric equilibrium $\left(\lambda_{i}^{m}=\lambda_{-i}^{m}\right.$ and $\left.g_{i}=g_{-i}\right)$ equation (18) reduces to:

$$
g_{i}=\lambda_{i}^{m}
$$

Clearly, this is identical to the decentralized level of public goods provision when $\alpha=0$, in which case there is no jealousy externality. In this last case, there is no 'identity' argument for CPGs and both centralized and decentralized provision of public goods is socially efficient.

\subsection{Strategic Delegation}

With respect to the policy making process, we follow Besley and Coate (2003) in that we assume that the median voter strategically delegates policy making to an agent. Delegation serves as a commitment to a policy stance that would not be credible when the median voter himself would be in office. The set up of the policy making game is that in the first stage a policy maker is selected by the median voter taking account of how the preferences of this policy maker affect the policy outcome. We assume that the median voter can choose from a set of potential policy makers where the optimal candidate is interior to this set and is available for office.

In the second stage the delegate in each group decides on the optimal level of CPGs. In this second stage, we consider two alternative policy making environments. In a decentralized policy making setting, the delegates non-cooperatively decide on the level of CPGS. In a centralized policy making setting, the delegates coordinate their policies and maximise joint welfare.

\subsubsection{Decentralized equilibrium}

Suppose that the median voter in $i$ has a continuum of candidates with $\lambda_{i}^{d}>0$ at her disposal for the delegation of policy making. The optimal candidate will solve: 


$$
\frac{d V_{i}^{m}}{d \lambda_{i}^{d}}=\frac{d h\left(g_{i}, g_{-i}, \lambda_{j}\right)}{d g_{i}} \frac{d g_{i}}{d \lambda_{i}^{d}}+\frac{d h\left(g_{i}, g_{-i}, \lambda_{j}\right)}{d g_{-i}} \frac{d g_{-i}}{d \lambda_{i}^{d}}-\frac{d g_{i}}{d \lambda_{i}^{d}}=0
$$

From (14) the median voter in $i$ anticipates that the equilibrium provision of public goods will be:

$$
\begin{aligned}
& g_{i}=\frac{1}{1-\alpha^{2}} \lambda_{i}^{d}+\frac{\alpha}{1-\alpha^{2}} \lambda_{-i}^{d} \\
& g_{-i}=\frac{1}{1-\alpha^{2}} \lambda_{-i}^{d}+\frac{\alpha}{1-\alpha^{2}} \lambda_{i}^{d}
\end{aligned}
$$

Combining (20), (21), and (22) we obtain:

$$
\frac{d V_{i}^{m}}{d \lambda_{i}^{d}}=\frac{\lambda_{i}^{m}}{g_{i}-\alpha g_{-i}} \frac{1}{1-\alpha^{2}}-\frac{\alpha \lambda_{i}^{m}}{g_{i}-\alpha g_{-i}} \frac{\alpha}{1-\alpha^{2}}=\frac{1}{1-\alpha^{2}}
$$

From (13) we know that $g_{i}-\alpha g_{-i}=\lambda_{i}^{d}$ so that the optimal preferences of the delegate in country $i$ are described by:

$$
\lambda_{i}^{d^{*}}=\lambda_{i}^{m}\left(1-\alpha^{2}\right)
$$

This shows that the median voter will delegate leadership to a group member with preferences weaker than herself. Using (15), in the symmetric equilibrium public goods supply will be:

$$
g_{i}=(1+\alpha) \lambda_{i}^{m}
$$

When compared to the decentralized equilibrium without delegation in (15), the level of conspicuous public goods is lower in the presence of strategic delegation. However, decentralized public goods supply is too high when compared to the socially optimal level.

\subsubsection{Centralized equilibrium}

When policies are coordinated at the centralized level, we assume that the delegates maximize their joint welfare. However, the delegation decision itself is not coordinated. Again the median voter solves (20). Recall also that in equilibrium the delegates set policy according to (18). Therefore we find that in equilibrium:

$$
\frac{d V_{i}^{m}}{d \lambda_{i}^{d}}=\lambda_{i}^{m} \frac{1}{g_{i}-\alpha g_{-i}} \frac{1}{1+\alpha}-\frac{\alpha}{g_{i}-\alpha g_{-i}} \frac{\alpha}{1+\alpha}=\frac{1}{1+\alpha}
$$

In the symmetric equilibrium from (18) we know that $g_{i}=g_{-i}=\lambda_{i}^{d}$ which gives the optimal preferences of the delegate of: 


$$
\lambda_{i}^{d^{*}}=(1+\alpha) \lambda_{i}^{m}
$$

This shows that the median voter will delegate leadership to a group member with preferences stronger than herself. In the symmetric equilibrium, public goods supply will be:

$$
g_{i}=\lambda_{i}^{m}(1+\alpha)
$$

In this stylized example, delegation to extremists undermines any benefit that may have resulted from centralisation. In contrast to the 'bargaining rationale', selection of extremists does come at a cost even when groups cooperate.

\section{The Expressive Rationale}

All three models discussed so far assume that voters select leaders as though they are decisive in bringing them into power. This assumes away the problem posed by the 'paradox of voting'. This paradox tells us that since the probability of determining the outcome of any reasonably large-scale election is effectively zero and there is a cost to voting, why vote? An argument commonly made (explained in great depth in Brennan and Lomasky (1993)) is the idea that the benefit obtained from voting is more one of consumption than investment. Voters obtain a direct expressive utility from voting, even though it will have no consequential effect upon the outcome of the election.

Does this matter? Following Riker and Ordeshook (1968) one might be tempted to say no. They argue that a feeling of duty is an expressive benefit which gets voters to the polls, but when they get there they choose instrumentally. If that is the case, the instrumental motivation underlying the previous three sections would be unaffected. Brennan and Lomasky and Brennan and Hamlin (2000) take a different view. Expressive motivation may not only provide sufficient benefit to vote, but also may determine how voters vote. There is no particular reason why the choice should be the same as that made instrumentally. Since one is not in a position to choose the political outcome that would leave them best off, why not instead choose policies or leaders that simply make them feel best, even if their choice would not be in their instrumental interest. This implies that voting may cease to be strategic and become more emotional than calculative. Note though that the underlying reasoning is rational since it is based on voters correctly perceiving that voting is non-decisive when they express their emotional preference. 
Hamlin and Jennings explore in detail two possible divergences from instrumental choice which would significantly alter the results discussed under the 'bargaining rationale'. The first is that instead of delegation to doves or hawks dependent upon the political environment, the median voters may simply select someone with preferences the same as her own regardless of the political environment. In terms of the model this means that conflict would exist in equilibrium up to $v=1 / 4$, even though from $v=1 / 6$ compromise equilibria are available. The second is the most worrying. That is that extreme hawks may be selected since they provide the strongest definition of group identity. This would mean that conflict would exist in equilibrium up to $v=1 / 2$. In either of the two cases, the weighing of the potential costs of not choosing doves is irrelevant as no voter can individually bring these costs into existence through exercising their voting choice. A similar analysis can be provided for the 'social psychological rationale'. Expressive selection of the median voter would provide for the same results as in section 4.1. Expressive selection of extremists would worsen the outcomes in (15) and (19), but (19) would no longer represent social optimality as $g_{i}$ would be set at the level preferred by an extremist. At the same time though, centralisation in the presence of expressive extremist choice would unambiguously improve welfare.

A discussion of expressive choice perhaps completes the circle and brings us back to the comments made in the opening paragraph of this paper. Perhaps emotions do dominate voting choice in conflictual societies, but not because group members do not choose rationally, but rather the nature of large group decision-making is not conducive to placing instrumental preferences ahead of the expressive. In the next section we will provide an additional representation of expressive choice by relating it to Rabin's (1993) theory of fairness. ${ }^{5}$

\section{Application to Northern Ireland}

This section will attempt to relate the four rationales to the recent history of Northern Ireland. In particular, we will make use of election results. Northern Ireland provides an excellent case study. There has been a long-lasting conflict between two

\footnotetext{
${ }^{5}$ The depiction of expressive choice in this paper is a negative one. This need not be the case and in other circumstances expressive choice could be viewed as a force for good. See Brennan and Hamlin (1999) for such an example.
} 
communities, there is very little cross-community voting, each community contains relatively moderate and extreme parties and there has been a major constitutional change (the 1998 Agreement) that entails greater political cooperation between the communities.

First, it would be useful to try and summarise what the four rationales would predict

- The 'information rationale' is itself rich in the level of information contained within it. It requires information on the variance of the incumbent party ideology and the mapping of policies into outcomes. Recall that when the variance of the former outweighs the variance of the latter, only hawks will find it electorally profitable to pursue extreme dovish policies as they will be trusted. Clearly it is very difficult to get detail on these two dimensions, but nonetheless we will argue that Cukierman and Tomassi's theory may throw some interesting light on electoral history in Northern Ireland.

- The 'bargaining rationale' is also extremely difficult to test as we lack an estimate of $v$. However, the 1998 Agreement did signal a move towards cooperative institutions between relatively equal groups. As such, the prediction is that moderates (for at least one of the groups) would be more likely to be selected preAgreement and extremists selected post-Agreement. We should also distinguish between the nature of extremist selection in this rationale versus that in the information rationale. In the latter, the reason hawks are attractive is because there is considerable variance in party ideology. Therefore, when they sound moderate it may be partly explained by the fact that the party actually does contain an influential, relatively moderate wing. In the bargaining rationale, there is no uncertainty for voters. Extremists are extremists and when they agree a moderate compromise it is simply as a result of the bargaining process.

- The 'social psychological rationale' also predicts moderation pre-Agreement and extremism post-Agreement. The reason is related, but different to the bargaining rationale in that negotiation post-Agreement is not about the distribution of political power but limiting the contest over identity. In contrast to the bargaining rationale we find the persistence of inefficiency in a centralised agreement. In the discussion to follow we will relate this to the idea of 'ethnic outbidding' and the debate regarding the merits of consociation. 
- Given that the expressive rationale is well founded but not well defined, it is harder to make predictions based upon it. Hamlin and Jennings argue that emotions are likely to be extremely important when voters select leaders and strong emotions may result in the selection of extremists. This might imply the selection of extremists regardless of the institutional arrangements. An alternative prediction, also involving emotion, but which links expressive choice more closely with behavioural economics is that of Rabin (1993). He discusses how people are motivated to hurt those who are hurting them and help those who are helping them. They will do so even at some cost to themselves. Crucially, such emotional behaviour is more likely the lower the material costs. Voting in large groups is clearly a very low-cost activity given the very low probability of being decisive in determining the outcome of the election. So we might predict that moderates will be selected when the other group selects moderates and extremists will be selected when the other group selects extremists. So this might lead us to expect the voting behaviour to be symmetric. This prediction seems close to the bargaining and social psychological rationales where moderation or extremism on both sides can be expected depending on the degree of cooperation between groups. However, in this case the reason for this voting outcome is emotional rather than materialistic. This would imply either moderate selection or extremist selection on both sides independent of $v$ or the nature of institutions. Furthermore, in the bargaining rationale symmetric selection of moderate leaders is only one of many potential equilibria that may emerge for $1 / 6<v<1 / 2$.

We show three tables with recent election results for Northern Ireland. The first is for Westminster elections and the second is for local elections covering the same period. Showing the local elections meets the objection that showing only the Westminster results is selective as the results for it may reflect different voting motives. We start the series in 1983 as that was the first time Sinn Fein (SF) participated in elections. ${ }^{6}$

\footnotetext{
${ }^{6}$ The data can be found at http://www.ark.ac.uk/elections/
} 
Table 1: Westminster election results in Northern Ireland 1983-2005

\begin{tabular}{|c|c|c|c|c|c|c|}
\hline & 1983 & 1987 & 1992 & 1997 & 2001 & 2005 \\
\hline UUP & 34 & 37.8 & 34.5 & 32.7 & 26.8 & 17.7 \\
\hline DUP & 20 & 11.7 & 13.1 & 13.6 & 22.5 & 33.7 \\
\hline SDLP & 17.9 & 21.1 & 23.5 & 24.1 & 21 & 17.5 \\
\hline SF & 13.4 & 11.4 & 10 & 16.1 & 21.7 & 24.3 \\
\hline Alliance & 8 & 10 & 8.7 & 8 & 3.6 & 3.9 \\
\hline
\end{tabular}

Table 2: Local election results in Northern Ireland 1985-2005

\begin{tabular}{|c|c|c|c|c|c|c|}
\hline & 1985 & 1989 & 1993 & 1997 & 2001 & 2005 \\
\hline UUP & 29.5 & 31.3 & 29 & 28 & 23 & 18 \\
\hline DUP & 24.3 & 17.7 & 17 & 16 & 21 & 30 \\
\hline SDLP & 17.8 & 21 & 22 & 21 & 19 & 17 \\
\hline SF & 11.8 & 11.2 & 12 & 17 & 21 & 23 \\
\hline Alliance & 7 & 6.9 & 8 & 7 & 5 & 5 \\
\hline
\end{tabular}

Both tables demonstrate a clear and large swing in votes from the moderate UUP to the more extreme DUP and from the moderate SDLP to the more extreme SF. The centrist Alliance party has been increasingly squeezed. The change in voting patterns clearly accelerated after the 1998 Agreement. Results in the three elections for the Northern Ireland Assembly also show this swing. Indeed, in March 2007 the previously unthinkable happened and power sharing in Northern Ireland was restored with DUP providing the first minister and SF the second minister.

Table 3: Assembly elections in Northern Ireland 1998-2007

\begin{tabular}{|c|c|c|c|}
\hline & 1998 & 2003 & 2007 \\
\hline UUP & 21.2 & 22.7 & 14.9 \\
\hline DUP & 18.1 & 25.6 & 30.1 \\
\hline SDLP & 21.9 & 17 & 15.2 \\
\hline SF & 17.6 & 23.5 & 26.2 \\
\hline Alliance & 6.5 & 3.7 & 5.2 \\
\hline
\end{tabular}


The recent literature on Northern Ireland is very large and the purpose of this section is not to review it. Rather, the purpose of this paper is to explore whether the four rationales we have outlined can provide an analytical framework towards answering two key questions. First, what has caused the swing to the extremes and second, is this a cause for concern? The rationales make some clear predictions with regard to these two questions and the task is to relate them to the Northern Ireland experience.

At the heart of the recent debate on Northern Ireland is the consociational nature of the 1998 Agreement and the extent to which this has been a force for good through the creation of peace versus the extent to which consociation cements ethnicity, prevents integration and thus does not allow 'normal' politics to emerge. Consociational theory stems from Lijphart (1969). It takes group identity as given and devises a constitutional agreement that incorporates this fact. Four components are identified; an inclusive executive, a legislature elected by proportional representation, group autonomy where possible and minority vetoes on issues of vital interest.

The facts of voting would seem to support those who fear increasing sectarianism. Voters have shifted towards relatively extreme parties. On the other hand, the facts 'on the ground' clearly show that the war appears to be over and the 1998 Agreement would, one might think, have appeared to have played a large part in securing peace. Positive and negative (or at least guarded) views have been expressed on the merits of the 1998 Agreement. For a positive perspective see Mitchell, O'Leary and Evans (2001), McGarry and O’Leary (2005a), McGarry and O’Leary (2005b), Mitchell, Evans and O'Leary (2006) and Tilley, Evans and Mitchell (forthcoming). For a more guarded perspective see Taylor (2001), Horowitz (2001 and 2002) and Lutz and Farrington (2006).

Crucial to the position that is taken in this debate is the extent to which one is concerned that the swing in the vote to the DUP and SF is a sign of increasing ethnicity and polarization as a result of hot-headed emotional attachment or rather that these parties are winning votes for cool rational reasons which do not necessarily imply a more polarized society. We now turn to the four rationales which provide an analytical framework in which we can analyse this debate.

The bargaining rationale provides a logic for the selection of extremists and one that implies no welfare loss. It could be argued that pre-1998 voters on both sides of the conflict perceived a cost of conflict $v$ that hawks on either side would be willing to incur but doves would not. Therefore the selection of moderates in the pre-1998 
period was primarily to achieve peace and by choosing moderates they had coordinated on an efficient equilibrium. If either side had deviated and selected DUP or SF as their major party, the weak bargaining position presented by the UUP or SDLP would have necessitated the selection of a more extreme party even at the cost of conflict. Peace had to be negotiated by moderates and as soon as this was achieved, the median voters on either side realised the necessity of voting for extremists. So post-1998, conflict costs had been eliminated so there was no welfare loss attached to selecting extremists.

Some objections could be made against the explanatory power of the bargaining rationale. First, the theory only works to the extent that there are unresolved issues that still require resolution and thus provide the incentive for the selection of hard-line negotiators. If the 1998 Agreement had closed all areas of negotiation this would be a valid criticism. However, we know that this was not the case. Key areas such as decommissioning, demilitarisation and policing were left unresolved so strong incentives were in place to select extremists post-1998. Second, while it is true that the DUP were not involved in negotiating the 1998 Agreement, SF were involved. This might cause us to review the sort of political equilibrium that existed pre-1998. One might argue that it was asymmetric such that the unionist community supported a more moderate set of representatives than the nationalist community. After 1998, the extremist equilibrium that is predicted comes to pass. Third, one might object that SF and DUP are not actually extreme. This point is repeatedly made in the papers which are positive with regard to consociation. They argue that DUP and SF are more moderate than is commonly perceived. However, it is still the case that they are more extreme than the rival parties within their community, so good strategic reasons exist for voting for them.

Nonetheless, a difference in the bargaining rationale and recent literature on Northern Ireland electoral history is apparent. In the former, these parties would be attractive for the very reason that they are clearly identified as at the most extreme point possible in the political space. It is because both groups choose groups like this that moderate outcomes are secured. The Northern Ireland literature instead suggests that it is not just the outcome emergent from the interaction of DUP and SF that is moderate, but they are in actual fact more moderate than they used to be and this actual moderation is important in attracting voters and allowing peace to be secured. 
The information rationale may help with explaining the changing vote patterns pre and post Agreement whilst recognising the possibility that the precise ideology of the political parties may be nebulous. Recall that the two key factors in determining incumbent party policy are the Hotelling effect and the expectations effect. Effectively, the former by moving to the centre ground increases votes and the latter by signalling the superiority of the other side's policy approach loses votes. When the variance in party ideology is bigger than the variance in the mapping of policies into outcomes, then it makes electoral sense for hawks to implement more dovish policies and doves to implement more hawkish policies. The intuition is that the move towards dovishness by a hawk is more likely to be interpreted as a genuine increase in moderation within the party and because the variance of policies into outcomes is low, the expectation effect is reduced because the expectation is that dovish policies will generally lead to dovish outcomes which is less appealing for the median voter.

This rationale arguably fits very well with recent Northern Ireland electoral history and would also address the seemingly moderate nature of DUP and SF as raised above. A plausible explanation for the decline in UUP support after 1998 is that they were a relatively dovish party, but with a large variance of internal ideology. Kaufmann and Patterson (2006) cover this in detail, but essentially a more hawkish wing of the party existed with Jeffrey Donaldson as its figurehead. It is also the case that although one might argue that there is some variation in terms of the mapping of policy into outcome, it would be hard to argue that this is large. These two factors would imply that pursuing a peace deal with SF was electoral suicide for UUP because the unionist electorate perceived the dove wing of the UUP to have become dominant thus rendering any agreement less credible. While the shift to the DUP after 1998 could be explained by the bargaining rationale, arguably a further contributing factor was the defection of Donaldson and other prominent unionists from UUP to DUP in 2004. This confirmed the DUP as having a wide range of ideology and thus any subsequent move towards moderation could be interpreted as a genuine shift within party ideology. This clearly raises the attractiveness of voting DUP for middle of the road Unionists and any agreement they make is more credible. This story of defection does not really work for the shift in voters from SDLP to SF. Perhaps for SF and also for DUP (aided by defections from UUP) the moderate voices within each party found confidence compared to the 1980's and created a perception that both parties contained a broader coalition of views than had once been thought. 
In term of the consociation versus integration debate, the information rationale highlights that hawks may actually be necessary to create a lasting peace agreement and the bargaining rationale suggests that the selection of hawks should be seen as a rational response to the establishing of cooperative institutions. Neither theory implies welfare losses from consociation. The 'social psychological rationale' does pick up on this concern. By focussing on the competition that may exist over group identity it recognises sources of welfare loss not directly related to violence. Furthermore, the theory predicts moderate selection in a non-cooperative state and selection of extremists in the cooperative state. The pattern of voting certainly conforms to the predictions of the rationale, but is there evidence that the shift towards DUP and SF is related to stronger group identity and increasing polarisation. Some commentators suggest that this may well be the case. A powerful example is the coverage in the Economist (April 12' ' 2006) in a piece entitled 'Still Troubled: Northern Ireland staggers towards normality.' The essence of the argument is that working class Protestant and Catholic are arguably even further apart than they were before 1998. They vote in large numbers for DUP and SF while middle-class abstention from voting is on the increase. This would suggest that, at least to some extent, the 1998 Agreement has not resolved the conflict significantly and as integrationists might argue if anything, the consociational nature of the Agreement has stoked increased polarisation. The Economist (April $3^{\text {rd }}, 2008$ ) repeated its guarded approval on the tenth anniversary of the 1998 Agreement. $^{7}$

The expressive rationale could also be viewed as consistent with observed voting patterns and welfare losses. At first sight, the expressive rationale would seem to be undermined by the shifting voting pattern post 1998 as this seems clear evidence of voters engaging in instrumental strategic delegation. ${ }^{8}$ However, if we combine expressive voting with Rabin's theory of fairness the move to the extremes could be viewed as a disturbing equilibrium where both sides are hurting the other by voting for extremists. Indeed, the Economist article suggests this as a motive for working

\footnotetext{
${ }^{7}$ Indeed, throughout this paper care has been taken to use the term the 1998 Agreement. The naming of the Agreement is itself ironically (but perhaps not surprisingly) subject to disagreement in the two communities. Nationalists refer to the Good Friday Agreement, a section of Unionists refer to the Belfast Agreement and a further section of Unionists claim not to recognize the 1998 Agreement and refer instead to the 2006 St Andrews Agreement as this involved the participation of the DUP.

${ }^{8}$ Strategic voting is harder to justify when the paradox of voting is accepted. The idea of voters engaging in strategic delegation creates the clear demarcation between the social psychological and expressive rationales.
} 
class Protestants voters. The welfare loss would exist because conflict costs are discounted by voters (as their vote is non-decisive) and conflict costs still exist in terms of the everyday interaction of the two communities even if organised political violence has been eradicated.

Nonetheless, it is the last point that should cause us to resist concluding that the integrationist concern with consociation has proved correct. There has been no crosscommunity, organised political violence since 1998. It could be argued that this has nothing to do with the 1998 Agreement since there had been very little political violence in the years preceding it as well. We would argue that this is not the case. The Agreement contained three strands. The first relates to the internal arrangements, in the spirit of the components outlined above such as an all-inclusive executive and a legislature elected by the single-transferable vote. Jennings (2007) argues that strands two and three have done much to create a cooperative atmosphere such that strand one is given room to operate. The second and third strands address external arrangements, the second relating to the North-South Ministerial Council and the third relating to the British-Irish Council. It could be argued that the North-South Ministerial Council is an important symbolic institution for the nationalist community and the British-Irish Council (an institution that brings together the states of the UK and Ireland alongside the devolved governments within the UK) is an important symbolic institution for the unionist community. In this sense, the 1998 Agreement could be viewed as an expressive constitution (Brennan and Hamlin (2002)), one in which the institutions created provide a continuing focus for expressive choice, but a choice that is more likely to achieve peace. This is because strands two and three have removed much of the heat from the conflict.

\section{Conclusion}

This paper has outlined four rationales that provide differing explanations for why we may see dovish parties dominate voting under certain circumstances and why we might observe hawk parties dominate voting under a different set of circumstances. The information and bargaining rationales are more sanguine regarding the welfare implications of shifts from moderate to more extreme voting than the social psychological and expressive rationales. We apply the theories to voting patterns in Northern Ireland and consider the welfare implications. It would clearly seem to be 
the case that Northern Ireland is in better shape now than before the 1998 Agreement, but some of the potential difficulties indicated in the social psychological and expressive rationales do seem to be borne out in practice. Nonetheless, the more positive perspective provided by the information and bargaining rationales would seem to win through and the idea that the popularity of DUP and SF is related to the fact that they are no longer viewed as having a fixed, extreme political standpoint provides support specifically for the information rationale. The contribution of this paper has been in the area of applied theory, but further exploration of the issues would benefit from data and future work might focus on survey questions which pin down more precisely exactly what has been motivating the voters (and non-voters) of Northern Ireland when making their electoral choice. This, in turn, would give us a clear idea of the extent to which we should be concerned about the increasing domination of DUP and SF. Furthermore, it would be instructive to investigate whether the rationales explored here could be applied to patterns of political support in other countries that have suffered ethnic violence and undergone constitutional reform.

\section{References}

Besley, T. and Coate, S. (1997) An economic model of representative democracy, Quarterly Journal of Economics, 112, 85-114.

Besley, T. and Coate, S. (2003) Centralized versus decentralized provision of local public goods: A political economy analysis, Journal of Public Economics, 87, 261137.

Brandauer, S. and Englmaier, F. (2006) A model of strategic delegation in contests between groups, unpublished

Brennan, G.and Hamlin, A. (1999) On political representation, British Journal of Political Science, 29, 109-127.

Brennan, G.and Hamlin, A. (2000) Democratic devices and desires. Cambridge University Press, Cambridge.

Brennan, G., Hamlin, A. (2002) Expressive Constitutionalism. Constitutional Political Economy, 13, 299-311.

Brennan G. and Lomasky L. (1993) Democracy and decision. Cambridge University Press, Cambridge. 
Bueno de Mesquita, B., Morrow, J.D., Siverson, R.M., and Smith, A. (2002) Political institutions, policy choice and the survival of leaders. British Journal of Political Science, 32, 559-590.

Bueno de Mesquita, B., Siverson, R.M., and Morrow, J.D. (2003) The logic of political survival. MIT Press, Cambridge, Mass.

Bueno de Mesquita, B. (2006) 'International conflict' chapter 46 in B.R. Weingast and D.Wittman (eds), Oxford Handbook of Political Economy. Oxford, Oxford University Press

Brown, R. (2000) Group Processes ( $2^{\text {nd }}$ edn). Blackwells, Oxford.

Chari, V.V., Jones, L.E. and Marimon, R. (1997) The economics of split-ticket voting in representative democracies. American Economic Review, 87, 957-976.

Cukierman, A. and Tomassi, M. (1998) When does it take a Nixon to go to China? American Economic Review, 88, 180-97.

Dur, R. and Roelfsema, H. (2005) Why does centralisation fail to internalise policy externalities?, Public Choice, 122, 395-416.

Frank, R. (1985). Choosing the Right Pond: Human Behavior and the Quest for Status, Oxford University Press, Oxford.

Garfinkel, M. and Skaperdas, S. (2007) "Economics of Conflict: An Overview," chapter 22 in T. Sandler and K. Hartley (eds.), Handbook of Defense Economics, Vol. 2 chapter 22 (Amsterdam: North Holland, 2007).

Hamlin A. and Jennings C. (2007) Leadership and conflict, Journal of Economic Behavior and Organization, 64, 49-68.

Horowitz, D.L. (2001) 'The Northern Ireland Agreement: Clear, consociational and risky', chapter 4 in J. McGarry (ed), Northern Ireland and the Divided World, Oxford, Oxford University Press.

Horowitz, D.L. (2002) Explaining the Northern Ireland Agreement: The sources of an unlikely constitutional consensus, British Journal of Political Science, 32, 193-220.

Jennings C. (2007) Political leadership, conflict and the prospects for constitutional peace. Economics of Governance, 8, 83-94.

Jennings C. and Roelfsema H. (2008) Civil conflict, federalism and strategic delegation of leadership, Journal of Peace Research, 45, 557-73.

Kaufmann, E. and Patterson, H. (2006) Intra-party support for the Good Friday Agreement in the Ulster Unionist Party. Political Studies, 54: 509-532.

Lijphart, A. (1969) Consociational Democracy. World Politics, 21: 207-25. 
McGarry, J. and O’Leary, B. (2006). 'Consociational Theory, Northern Ireland's Conflict and its Agreement: Part 1. What Consociationalists Can Learn from Northern Ireland', Government \& Opposition, 41: 43-63.

McGarry, J. and O’Leary, B. (2006). 'Consociational Theory, Northern Ireland's Conflict and its Agreement: Part 2. What Critics of Consociation Can Learn from Northern Ireland', Government \& Opposition, 41: 249-277.

Mitchell, P., O’Leary, B. and Evans, G. (2001) Northern Ireland: Flanking extremists bite the moderates and emerge in their clothes. Parliamentary Affairs, 54: 725-742. Mitchell, P., Evans, G. and O’Leary, B. (2006) Extremist outbidding in party systems is not inevitable: Tribune parties in Northern Ireland, unpublished.

Persson, T., Tabellini, G. (1992) The politics of 1992: Fiscal policy and European integration. Review of Economic Studies, 59, 689-701.

Rabin, M. (1993) Incorporating fairness into game theory and economics, American Economic Review, 83, 1281-1302.

Riker, W.H., Ordeshook, P.C. (1968) A theory of the calculus of voting. American Political Science Review, 62, 25-42.

Skaperdas, S. (2006) 'Anarchy', chapter 48 in B.R. Weingast and D.Wittman (eds), Oxford Handbook of Political Economy. Oxford, Oxford University Press.

Tajfel, H. (1981) Human Groups and Social Categories. Cambridge University Press, Cambridge.

Taylor, R. (2001) 'Northern Ireland: Consociation or Social Transformation', chapter 2 in J. McGarry (ed), Northern Ireland and the Divided World, Oxford, Oxford University Press.

Tilley, J., Evans, G. and Mitchell, C. (forthcoming) Consociationalism and the evolution of political cleavages in Northern Ireland, 1989-2004. British Journal of Political Science, 38, 699-717. 


\section{Strathclyde Discussion Papers 2008 Series}

08-01 Nikos Pappas

Can Migrants save Greece from Ageing? A Computable General Equilibrium Approach Using G-AMOS.

08-02 Colin Jennings and Iain McLean

Political Economics and Normative Analysis.

08-03 Colin Jennings and Hein Roelfsema

Civil Conflict, Federalism and Strategic Delegation of Leadership.

08-04 Roy Grieve

Keynes, Sraffa and the Emergence of the General Theory: Some Thoughts.

08-05 Roy Grieve

Adam Smith's Concept of Productive and Unproductive Labour: An Interpretation.

08-06 Roy Grieve

'Economic Geometry': Marshall's and Other Early Representations of Demand and Supply.

08-07 Karen Turner

A Computable General Equilibrium Analysis of the Relative Price Sensitivity Required to Induce Rebound Effects in Response to an Improvement in Energy Efficiency in the UK Economy.

08-08 Michelle Gilmartin, Kim Swales and Karen Turner

A Comparison of Results from MRIO and Interregional Computable General Equilibrium (CGE) Analyses of the Impacts of a Positive Demand Shock on the 'CO2 Trade Balance' Between Scotland and the Rest of the UK. 